Max-Planck-Institut für demografische Forschung

Max Planck Institute for Demographic Research

Doberaner Strasse 114 - D-18057 Rostock - GERMANY

Tel +49 (0) 3812081 - 0; Fax +49 (0) 3812081 - 202;

http://www.demogr.mpg.de

MPIDR WORKING PAPER WP 2000-006

AUGUST 2000

\title{
Private car use in Austria by demographic structure and regional variations
}

Ulf Christian Ewert (ewert@ demogr.mpg.de)

Alexia Prskawetz (fuernkranz@ demogr.mpg.de)

This working paper has been approved for release by:

Alexia Fürnkranz-Prskawetz (fuernkranz@demogr.mpg.de), Head of the Research Group on Population,

Economy, and Environment

(C) Copyright is held by the authors.

Working papers of the Max Planck Institute for Demographic Research receive only limited review. Views or opinions expressed in working papers are attributable to the authors and do not necessarily reflect those of the Institute. 


\title{
Private car use in Austria by demographic structure and regional variations*
}

\author{
Ulf Christian Ewert and Alexia Prskawetz
}

Max Planck Institute for Demographic Research

\author{
ABSTRACT \\ 1. INTRODUCTION \\ 1.1. Motivation \\ 1.2. Private car use as environmental (mis)behaviour \\ 1.3. Regional differences in car use \\ 1.4. Data \\ 1.5. Aim of the study \\ 2. A MODEL TO EXPLAIN REGIONAL DIFFERENCES IN CAR USE \\ 2.1. General design of the model \\ 2.2. Environmental behaviour as the target component of the model \\ 2.3. Direct demographic effects \\ 2.4. Direct control factor effects \\ 2.5. Mediated (indirect) demographic effects \\ 3. PATH ANALYSIS \\ 3.1. Methodological remarks \\ 3.2. Goodness of fit \\ 4. DETERMINING MECHANISMS OF REGIONAL LEVEL CAR USE \\ 4.1. Direct demographic impacts with and without controlling for other variables \\ 4.2. The impact of non-demographic factors \\ 4.3. Effects of the mean age \\ 4.4. Effects of regional distributions of employment status and living arrangements \\ 4.5. Effects of population density and population growth \\ 4.6. Effects of mean educational level \\ 4.7. Interaction of affluence, commuting activities, engine technology, and car use \\ 5. CONCLUSIONS \\ REFERENCES
}

\begin{abstract}
Due to its manifold impact on the environment private car use represents an important dimension of environmental behaviour in industrialized countries. Obviously, private car use is related to demographic characteristics of households such as the life-cycle stage and the living arrangement the household lives in. In addition systematic regional differences of private car use have to be taken into account. In this paper a causal model is derived, which aims to explain regional variations in car use (as measured by the distance driven) by regional demographic differences and region-specific control factors such as attitudes towards car use, car technology, and institutional factors. Using aggregate data from an household survey in Austria and data from Austrian official statistics causal effect coefficients are then estimated. By applying path analysis the estimated effects of regional demographic characteristics on region-specific car use can be decomposed into direct and indirect effects, with the latter effects being mediated by the control factors. Almost no significant direct demographic effect on car use can be found. Region-specific averages of distances driven are best predicted by using the considered control factors as predictor variables. Nevertheless, many of the presumed indirect effects turn out to be of importance. For instance, the regional mean age of household heads can be discerned as a key factor of demographic effects on car use since it significantly influences several of the region-specific control factors. Moreover our results evidence that the regional pattern of car use is covered by various combinations of control factors.
\end{abstract}

\footnotetext{
* A preliminary version of this paper was presented at the meeting of the Population Association of America in Los Angeles (session on Population and Environment: Demographic Dimensions), March 2000. The authors are grateful for comments and suggestions made by the participants at this session. In particular the authors would like to thank the discussant Warren C. SANDERSON. Karl BREHMER takes the credit for polishing the English.
} 


\section{INTRODUCTION}

\subsection{Motivation}

Most studies on the population-environment nexus focus on developing countries, where natural resources often still constitute the means of subsistence and a close link between population variables and environmental degradation seems obvious. But since major polluting activities (e.g. $\mathrm{CO}_{2}$ emissions) are not restricted to developing countries, one needs to investigate the interrelation between population and the natural environment in highly developed countries as well (see, e.g., Cramer, 1998, Cramer and Cheney, 2000, on air pollution in California).

Mainstream research in environmental economics holds institutional arrangements - and more generally the economic infrastructure - responsible for environmental damages in developed countries. Aggregate demographic factors are only included insofar as they determine the demand for goods that ultimately have a negative impact on the environment. But as has been stressed in the environmental sociology literature, individual-level characteristics are important for understanding environmental attitudes and the resulting environmental behaviour. Besides individual characteristics (such as age, education, etc.), aggregate level features of social structure and social networks have to be accounted for, along with past social choices and ongoing social commitments that constrain behaviour (Engel and Pötschke, 1998, and Lutzenhiser and Hackett, 1993).

In this paper we aim to explain environmental behaviour from a demographic perspective. As an example of environmental behaviour we have choosen car use in private households in Austria. That there are pronounced differences in travel patterns by gender, age, and income is obvious, as has recently been shown by Carlsson-Kanyama and Linden (1999) for Sweden, for example. To obtain a more compact representation of the individual's social embeddedness one should add further household characteristics like household size, life-cycle stage of the household head and current living arrangements. All of these factors should determine the number of cars per household, the brand (Krause, 1997, Wellner, 2000), and the specific technical features of the car as well as the more general decision whether a household owns private cars or not (Mikl-Horke and Leuker, 1978) and how long households indend to hold a vehicle (Yamamoto and Kitamura, 2000). In addition to these household-level characteristics, factors relating to institutional factors such as the local infrastructure will certainly determine private car use and therefore have to be included in a model that seeks to explain environmental behaviour.

\subsection{Private car use as environmental (mis)behaviour}

Cars have two adverse effects on the environment (cf. Canzler and Knie, 1994, 16-23, Lorbeer, 1996). The prerequisite for car use, the construction of road traffic infrastructure, implies a very intensive use of land, while the actual use of car creates noise pollution and a variety of air-polluting emissions. Spatial mobility that relies on the use of private cars can thus be defined as environmental misbehaviour, a mode of behaviour with negative consequences for the natural environment. In Austria private cars are used by an increasing proportion of households, and during the 1980's they were also used to a higher degree in total. The total distance travelled by private cars has increased from 28.3 billion $\mathrm{km}$ (with 2.25 million cars) in 1980 up to 43.9 billion km (with 3.1 million cars) in 1991, which is an increase of total distance of about $55 \%$ and an intensity shift from 12,578 to $14,161 \mathrm{~km}$ covered annually per car. Thereafter, up to 1995, there was only a marginal increase in yearly total covered distances to 44.1 billion km (cf. Umweltbundesamt, 1998, 100-101, Tables 30, 31).

Some attempts have been made to reduce emissions since the early 1970's: carbon-monoxide emissions of cars and other sorts of motor vehicles have been subject to environmental regulations since 1970, and the same is true of the emission of sulphur-dioxide since the early 1980's, although all improvements in sulphur-dioxide emissions have been completely undermined by the increasing share of cars with diesel engines (see Umweltbundesamt, 1998, 105). In addition, the environmental relevance of emissions of other gases has increased over the course of time as illustrated in Figure 1. Clearly of importance is air pollution due to carbon-dioxide, a gas which is suspected of being a major cause of global warming. The total share of carbon-dioxide emissions in Austria due to road traffic has consistently risen from $17.8 \%$ in 1985 to $24.4 \%$ in 1995 (see Österreichisches Statistisches Zentralamt, 1997, 196, Table 14.09). Moreover, the total share of carbon-dioxide emissions caused by private road traffic is greater over the course of time than that of emissions from commercial and public transport motor vehicles. This is also the case as regards carbon-monoxides and non- 
methanol-volatile-organic-compounds (NMVOCs) (see Umwelbundesamt, 1998, 105-108, Figures 38-42).

This increase in air pollution has occured despite of the fact that awareness of the environment has become much keener in the same period of time, as it has in many other industrialized countries

Share of total emissions due to traffic in Austria (1980-1995)

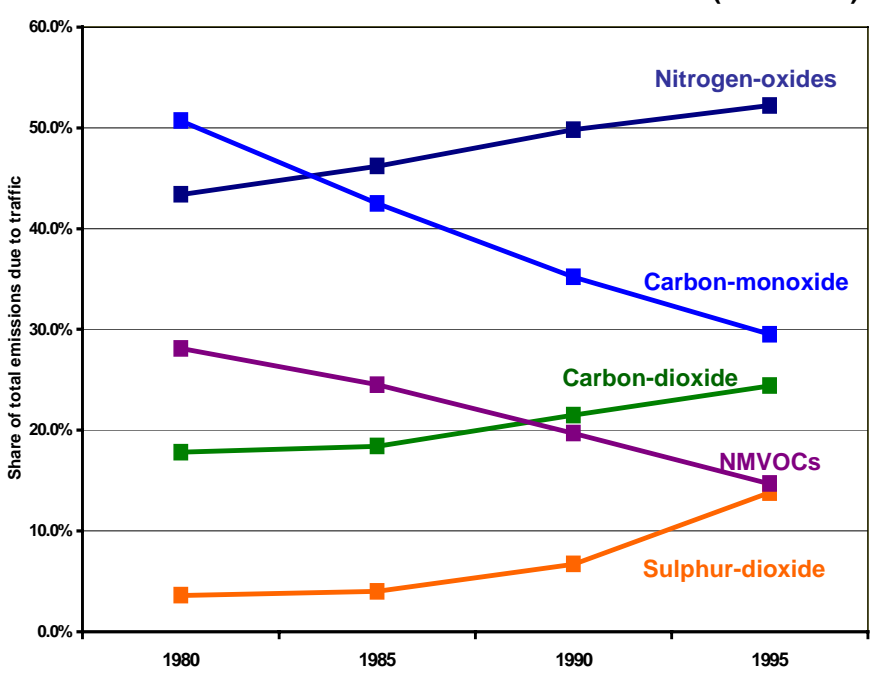

Fig. 1: Shares of total emissions of various gases due to road traffic in Austria 1980, 1985, 1990, 1995.

Source: Data taken from Österreichisches Statistisches Zentralamt, 1997, Table 14.09, 196. (cf. in the case of Germany, e.g., Held, 1984, Schupp and Wagner, 1998, Citlak and Kreyenfeld, 1999). According to the common distinction of so-called 'lowcost' and 'high-cost' situations the decision to own a car and to use it, obviously represents a 'high-cost' situation for a household since, once taken, this decision is very costly to reverse. Research on other sorts of environmental behaviour such as recycling activities or proenvironmental consumer behaviour has shown that in 'high-cost' situations environment-friendly behaviour is usually not correlated to environment-friendly attitudes. Decision takers mainly consider economic factors such as prices or opportunity costs as relevant decision parameters (cf. Kirchgässner, 1992, Diekmann and Preisendörfer, 1992, 240-241, Preisendörfer, 1998, Mensch 2000, 247251). In the case of car use, car owners usually evaluate single journeys with their car by marginal costs, whereas they are obliged to pay total costs when using alternative means of transport (Canzler, 2000, 193).

\subsection{Regional differences in car use}

In Austria, a considerably large proportion of the variation in overall private car use can be explained by regional differences - car use being measured in terms of the total distance covered annually per household with the first two cars. These differences may be the result of region-specific demographic, geographic, economic and institutional factors.

In order to cover the regional spread of environmental behaviour we refer to the European Union's spatial classification system NUTS (Nomenclature des unités territoriales statistiques - Nomenclature of territorial units for statistics). Following the hierarchy of this classification, Austria can either be subdivided into the three regions of East-, Southeast- and West-Austria (NUTS-1), nine federal states (Bundesländer) (NUTS-2) or 35 local areas (NUTS-3) (see the legend in Figure 2). Although it is the NUTS-2 level that is the EU's official focus of regional planning (cf. Heigl and Mai, 1998, 294, van der Gaag, van Imhoff, van Wissen, 2000, 2), NUTS-3 areas seem to be the more appropriate units for analysis because some of the Austrian federal states show considerable internal differences in geography and climate. For instance, the northwestern part of Styria is covered with high alpine mountains, whereas the southernmost part of this federal state exhibits an almost subtropical climate. Furthermore, since NUTS-3 areas are relatively small - the spatial extent of NUTS-3 areas ranges from 415 to 4,614 square $\mathrm{km}$ - their internal heterogeneity as regards living conditions should also be relatively small in most cases in comparison to the much wider NUTS-2 regions.

Interregional variation is clearly evident as illustrated by regional average levels of selected sociodemographic variables. In 1997 the average age of household heads within NUTS-3 areas ranged from 49.41 years up to 55.20, average household size ranged from 2.02 up to 3.49 persons per household, and average educational level, measured on a scale ranging from 0 (no school leaving qualification) to 8 (university degree), ranged from 1.89 to 3.19 .

Average car use, as the primary dimension of environmental behaviour in our study, varies tremendously among NUTS-3 areas as well. It is lowest with 14,211 km per household (with up to two cars) during a one-year period in 1996/97 in the westernmost area Rheintal-Bodenseegebiet and highest, with 21,564 km per household in the area of Südburgenland. 
To better capture the potential and the extend of environmental pollution we derive two parallel classifications of NUTS-3 areas based on various dimensions of car use. A combination of the share of households that own a car and the average number of cars per household in each region yields a four-type classification that captures the potential for car use (Classification A). Complementarily, a combination of the average distance driven and the corresponding intraregional variation constitutes a second classification (B), which reflects differing degrees of environmental pollution (see Table 1).

\begin{tabular}{|c|c|c|c|c|c|}
\hline \multicolumn{3}{|c|}{$\begin{array}{c}\text { Classification A } \\
\text { Degree of potential car use }\end{array}$} & \multicolumn{3}{|c|}{$\begin{array}{c}\text { Classification B } \\
\text { Degree of environmental pollution }\end{array}$} \\
\hline & $\begin{array}{c}\% \text { of households that own } \\
\text { a car }\end{array}$ & $\begin{array}{c}\varnothing \text { number of cars per } \\
\text { household }\end{array}$ & & $\varnothing$ distances driven & $\begin{array}{l}\text { intraregional variation } \\
\text { of distances driven }\end{array}$ \\
\hline (1) & below & below & (1) & below & below \\
\hline (2) & below & above & (2) & below & above \\
\hline (3) & above & below & (3) & above & above \\
\hline (4) & above & above & (4) & above & below \\
\hline
\end{tabular}

Tab. 1: Classifications of NUTS-3 areas in order to classify potentials of car use and the degree of environmental pollution. 'Below' and 'above' is measured with reference to the overall national averages of the characteristics.

Negative consequences for the environment should be most evident in type-4 regions. Here both the share of car owning households and the average number of cars per household are above national average, and cars are used homogeneously with an above-average intensity. In contrast, environmental pollution should be smallest in type-1 regions. Here the potential for car use is below national averages and cars are used homogeneously with a below-average itensity. For pro-environmental policy purposes that intend to diminish environmental consequences of car use, type-4 regions are most difficult to handle because almost every household would have to be induced to reduce both its number of cars and its actual car use.

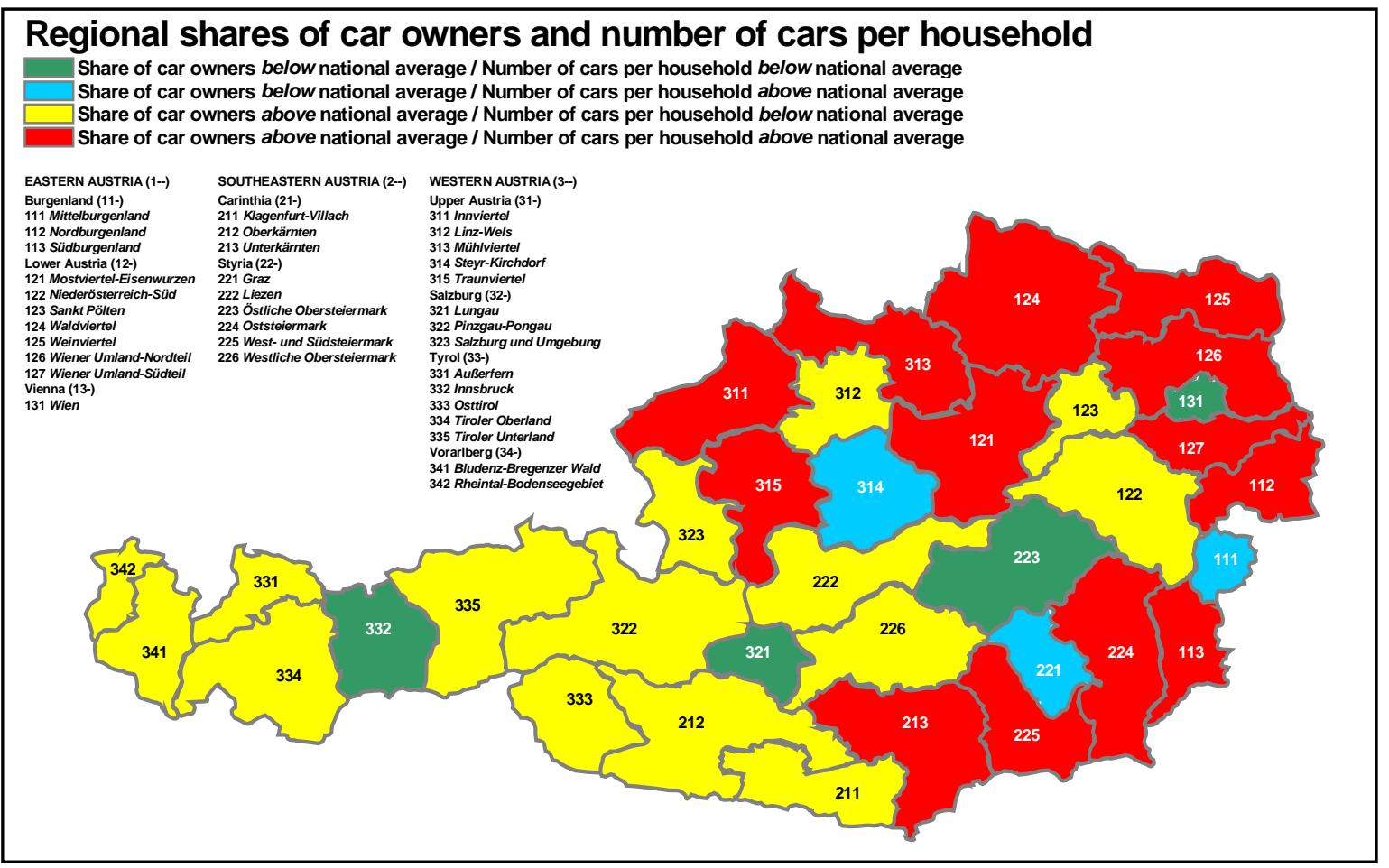

Fig. 2: Spatial pattern of car ownership and average number of cars per household.

Source: Authors own calculations, based on the Austrian micro-census as of June 1997 with NUTS-3 pattern taken from Österreichisches Statistisches Zentralamt, 1996.

Empirically, both classifications are correlated significantly (Spearman's rho $=.476, p \leq .01$ ), that is in many regions a high degree of car use potential means that also a high degree of environmental pollution as a consequence of private car use occurs. But geographic differences have to be considered. The spatial distribution of the four types of NUTS-3 areas as defined by classification A and B in Table 1 and displayed in Figures 2 and 3 shows a relatively clear geographical pattern. In most NUTS- 
3 areas the share of households owning at least one private car is above the national share of $72.2 \%$. But, only in the East, Northeast and Southeast this coincides with above-average numbers of cars per household. Regions with a comparatively high aggregate environmental pollution (Classification B type-3 and type-4 NUTS-3 areas) are located exclusively in the East, Northeast and Southeast. The environmentally more favourable patterns of car use - type-1- and type-2 regions - are mostly concentrated in the western and central parts of Austria.

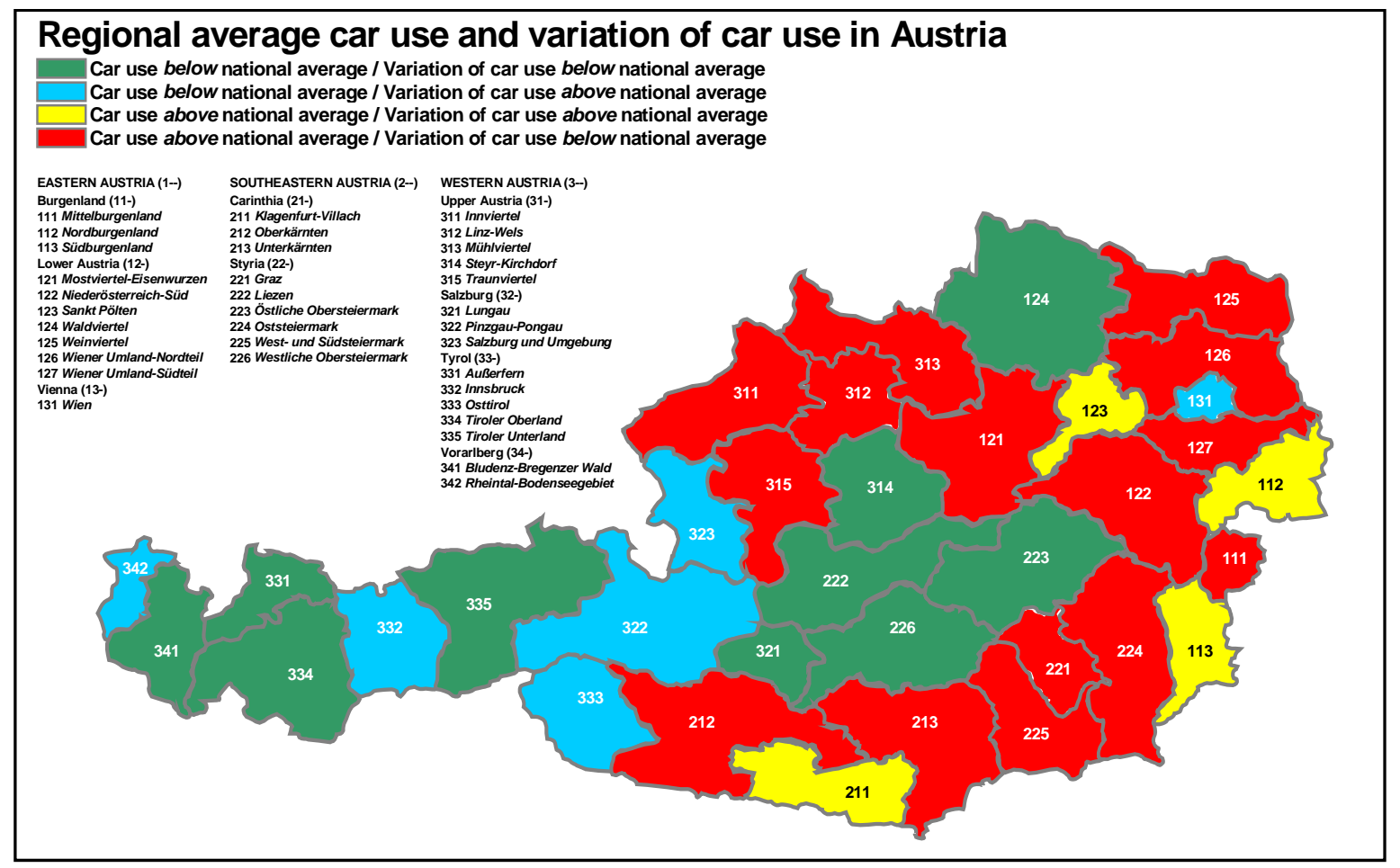

Fig. 3: Spatial pattern of regional average car use and intraregional variation of car use.

Source: Authors own calculations, based on the Austrian micro-census as of June 1997 with NUTS-3 pattern taken from Österreichisches Statistisches Zentralamt, 1996.

However, this classification of overall environmental impact serves only as a very rough approximation for environmental pollution resulting from car use, as it only focuses on private car use for resident households. Especially economically very active regions and regions where tourism is a very important economic factor attract motor vehicle traffic from neigbouring regions or from abroad (for attempts to reduce car use in connection with tourism in the federal state of Salzburg see e.g. Sicher, 1999).

\subsection{Data}

The present study is based on the Austrian micro-census of June 1997. The micro-census is a representative household survey of $1 \%$ of all Austrian dwellings, which is conducted quarterly. It provides information on household demographic characteristics such as total household size, number of children, age of the household head, and socio-economic factors like education and employment status of the household head. The sample size is in the order of about 30,000 dwellings, and each quarter an eighth of all addresses are replaced by new ones. In the particular case of June 1997 the survey contained 22,648 unweighted valid cases (for a more detailed description see Österreichisches Statistisches Zentralamt, 1998a, 3-8).

The basic programme of the micro-census is accompanied by alternating supplementary blocks of questions that adress special topics of interest. Special programmes on household energy consumption have been a regular part of the micro-census since 1975 and were conducted up to 1989 on a two-year cycle as part the March survey. The regular repetition was then changed to a four-year cycle, so that during the 1990's the results of only two special programmes on energy consumption are available, one from March 1993 and the other from June 1997 (cf. Simhandl, 1998, 761). The special programme on 'Energy Use in Households', which was part of the questionnaire in June 1997, also provides (in addition to household energy use related to heating) information on the private car use, fuel consumption, and details concerning the technical features of cars in households. Based on 
these data it is possible to reconstruct in part the travel behaviour of private households. In particular, the following characteristics can be defined: (1) how many kilometers households drove with their first and, if present, their second car in the course of the year before the interview; (2) how much fuel their car(s) used on average; (3) what sort of engine (petrol or diesel) their car(s) is/are equipped with; (4) whether their car(s) comply with environmental regulations or not. These data do not include information on the specific activities for which cars were used, so concrete travel patterns cannot be constructed.

Because we aim to control for characteristics referring to the social environment and economic infrastructure, we define a set of macro-level data such as population density, regional affluence, unemployment rate, etc.. These data are available from the statistical yearbooks of the Austrian Bureau of Statistics (up to 1999 Österreichisches Statistisches Zentralamt, from 2000 onwards Statistik Österreich). We restrict the analysis to the NUTS-3 spatial classification level in order to balance the needs for regional dis-aggregated analysis, data availability, and conformity of focused regional units to an EU-wide classification. In the more dis-aggregated spatial division into political districts (Politische Bezirke) there is a lack of data availability for some population variables, and furthermore this division does not fit very well into the NUTS spatial classification.

\subsection{Aim of the study}

The aim of the study is to quantify the effect of demographic characteristics on environmental behaviour as measured by private car use in Austria. More specifically, we ask whether regional variations in environmental behaviour can be explained by regionally differing demographic conditions? We aim to determine the environmental effect of demographic characteristics by controlling for direct and mediating effects of economic and institutional factors. The regional perspective is given preference to here because even a very detailed household-level regression that also covers the presumed dependence of demographic impact on regional differences (multilevel design) is able to explain only slightly more than about $20 \%$ of the variance in environmental behaviour. ${ }^{1}$ Another reason for favouring the regional level for a structural approach is that policies aimed at reducing car use have to be targeted to institutional factors and infra-structural development, which then in turn will effect environmental behaviour.

It is our intention to provide a conceptual framework for the analysis of regional-level interrelations between demographic characteristics and environmental behaviour in industrialised countries - which can then be applied to other European Union countries as well. The NUTS-3 level of spatial classification seems the most favorable classification to use if one wishes to make EU-wide regional comparisons. While multilevel analysis often does not justify the preference of specific aggregation units, the present research design should provide also a very first test for the relevant level to be considered in a multilevel analysis.

In the following section we propose a causal structural model that relates the average environmental behaviour in each region (as measured by average car use and petrol consumption) to regionspecific demographic characteristics, economic and institutional factors, and degrees of technical car equipment. Then we present estimations of the model with data from the Austrian microcensus as of June 1997 and discuss structural demographic effects on average environmental behaviour within the framework of path analysis.

\footnotetext{
1 In this framework, environmental behaviour is measured in terms of distances driven per household with the first two cars during the period of one year. A linear regression model with car technology variables (number of cars per household, petrol vs. diesel engine, degree of use of catalytic converters) as regressors yields a $R^{2}$ of .172 . This amount of explained variance can be only marginally increased by introducing also household head- and household-specific characteristics, such as age, educational level, employment status, size of household etc. $\left(R^{2}=.209\right)$. A further distinction of regional differences by inclusion of regional dummy-variables also leads only to a marginal further increase of the explained proportion of variance $\left(R^{2}\right.$ $=.214)$. In a very similar study of car use for Switzerland even a smaller coefficient of determination $\left(R^{2}=.080\right)$ was obtained in a regression of annually driven distances with household-specific characteristics and environmental attitudes as determinants (cf. Franzen, 1997, 87).
} 


\section{A MODEL TO EXPLAIN REGIONAL DIFFERENCES IN CAR USE}

\subsection{General design of the model}

To quantify the explanatory power of demographic factors for environmental behaviour, with both variables being represented by their average regional level, we build up a 'multidimensional' model. In this framework we decompose the demographic effect on environmental behaviour into direct and indirect parts. Indirect parts of the effect are either represented by control factors or they are transmitted through the interplay of control factors and demographic factors. In addition to region-specific environmental behaviour and demographic structure we consider three groups of control factors (see Fig. 4): manifested attitudes towards car use, car technology, and institutional factors.

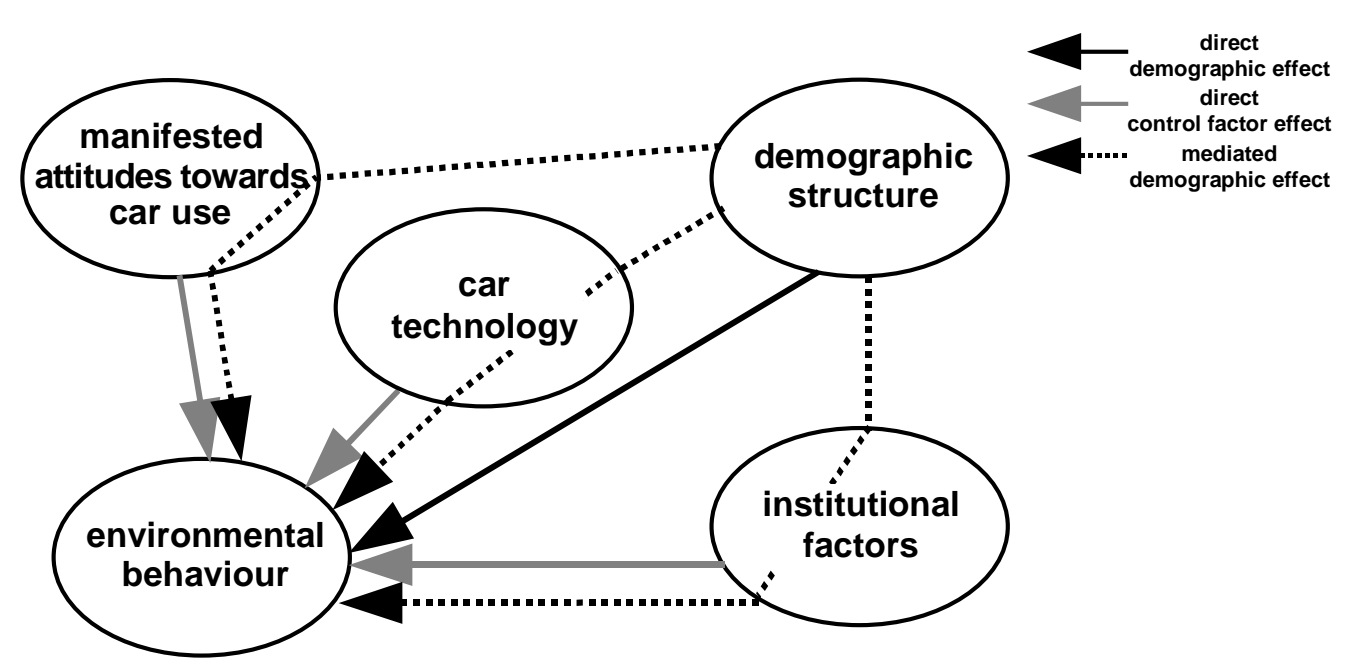

Fig. 4: Regional-level model of demography-environmental behaviour interrelations.

We include these control factors since the regional demographic structure will neither directly nor solely determine regional levels of environmental behaviour. For instance, the demographic structure may more likely explain regional levels of car technology which ultimately determine regional levels of car use. Similarly, the demographic structure may explain region-specific economic indicators and these will in turn determine regional levels of car use. Also a strong regional segregation of living forms can be observed in Austria. House ownership is more prevalent in rural areas and these are in turn regions with high commuting activities and, consequently, higher levels of car use.

Our methodological framework is closely related to structural approaches that aim to decompose the environmental impact into effects caused by population structure, economic structure, and production technologies. Most of these studies are based on aggregate regional-level data as the I-PAT identity (Impact-Population-Affluence-Technology) first proposed by Ehrlich and Holdren in 1971 and later on revised and extended by various authors (e.g. MacKellar et al., 1995, and Preston, 1996). An example of a more refined model is the POET model (Population-Organization-Environment-Technology) (Catton, 1987, Bailey, 1990), which also includes institutional factors in addition to population structure and production technologies - and unlike the I-PAT identity, it focuses on the multiple interactions between these factors. The economic model of Environmental Kuznets Curve (see List and Gallet, 1999), directly tests for an inverse U-shaped relationship between environmental impact and economic variables such as the standard of living, but ignoring completely demographic factors.

Compared to the I-PAT identity, our setup focuses on a more disaggregated regional level and it explicitely tests for causal interrelationships. But these causal interrelations between various components that effect environmental behaviour are restricted to a smaller number and are defined in a unidirectional way, in contrast to the POET model. To verify the significance of the proposed causal relationships we apply path analysis (a similar approach is adopted in Black, Stern and Elworth, 1985).

\subsection{Environmental behaviour as the target component of the model}

Environmental behaviour is represented by information on private car use of households. We use two dimensions of car use: (1) intensity and (2) efficiency. The average distance driven (in $\mathrm{km}$ ) with the first two cars during the period June 1996 up through June 1997 determines the intensity of car use. 
Among all households interviewed, about $25.5 \%$ indicated they had no car, and about $8 \%$ of the households did not give reliable answers. We therefore corrected for the selectivity of households on which the formation of the average car use intensity could be based.1 Efficiency of car use is measured by the average fuel consumption (in litres) for the first two cars during the same period. For NUTS-3-regional specific averages, the same correction procedures are applied as were for car use intensity.

We expect the fuel consumption to be increased by the distance driven. This direction of causality is justified since car use intensity will definitely feed back on car use efficiency. 2 We are thus interested in determining whether an increase in car use intensity leads to a proportional decrease in car use efficiency.

\subsection{Direct demographic effects}

The demographic structure of each region is measured by six factors: population density as of 1991 and population growth rate during the period 1981-19913, average age and average educational level of household heads, and two indices that capture the relevance of the employment status of household heads and the pattern of living arrangements.

The educational level of household heads is measured on a scale ranging from 0 (no school leaving qualification) to 8 (university degree). The average educational level and age of household heads in each NUTS-3 area is derived by averaging across all households within a region.

Based on the available information - keeping in mind that we are interested in relating differences in the employment status to differences in car use - we have opted for three categories of the employment status of the household head: (a) gainfully employed, (b) retired, or (c) neither of the two. Denoting the relative regional frequencies of each category by $q_{i 1}, q_{i 2}$, and $q_{i 3}$ we define the following measure of entropy, which represents the relative disparity of households forms in each region by the employment status of the household head.

$$
C_{i}^{G E}=1-\left[-\left(\sum_{j=1}^{k} q_{i j} \ln q_{i j}\right) / \ln k\right] \quad \forall i=1, \ldots, 35 ; k=3
$$

where the subscript i denotes the region, the subscript $j$ the employment category, and the superscript 'GE' stands for 'gainfully employed'. Since the first category $q_{i 1}$ (being gainfully employed) is dominant in all regions, a high value of the entropy measure implies the dominance of households with a gainfully employed head in addition to the standard interpretation that there is a higher disparity across the employment status in the region under consideration. 4 In contrast to common employment rates, the entropy measure also captures the distribution among relative frequencies of employment, unemployment, and retirement.

To capture the disparity of living arrangements in each region we define four different groups: (a) single-person households, (b) couples without children, (c) couples with children and (d) single parents. While (b) and (c) represent traditional forms of living arrangements, the presence of a significant number of households belonging to groups (a) and (d) is characteristic for modern societies. Since

1 For only 15,028 households out of a total of 22,648 households, distances driven are available. 5,783 households reported, that they did not own a car at all, and some other 1,837 households reported, that they did own a car, but did not report there intensity of use. NUTS-3 specific averages have been derived by applying a Heckman-type correction procedure in order to correct averages with NUTS-3-specific propensities to (a) own a car, and (b) to report the intensity of use throughout the year before the interview. Both sets of propensities were assumed to be independent of each other, so that the calculated inverted Mill's Ratios out of Probit-Regressions (a) on the propensity to own a car, and (b) on the propensity to report distances driven were added.

2 From a methodological point of view it is also essential to assume causality following this direction, since we derive the variable on car use efficiency by first multiplying for each car in a household the information on distances driven times average fuel use und then taking the mean value in each region across all households.

3 The choice of 1981 and 1991 is simply based on the fact that these are the years in which the Austrian census was conducted and reliable information on these variables is available.

4 The measure $\mathrm{C}_{i}^{\mathrm{GE}}$ is significantly correlated to the share of households with gainfully employed head $(r=.531 ; p \leq .01)$ and with the share of households where the head is neither gainfully employed nor retired $(r=-.864 ; p \leq .01)$. The bivariate correlation to the share of households with a retired head is not significant $(r=-.169)$. 
either living arrangement (a) or (c) dominates in most regions, we build up an entropy measure that aims to capture this disparity. Denoting the relative frequency of these four categories in each region $\mathrm{i}$ by $p_{i 1}, p_{i 2}, p_{i 3}$ and $p_{i 4}$ we define the entropy measure

$$
C_{i}^{L A}=\left\{\begin{aligned}
1-\left[-\left(\sum_{j=1}^{k} p_{i j} \ln p_{i j}\right) / \ln k\right] & \text { if } \max \left(p_{i j}\right)=p_{i 1} \\
-1+\left[-\left(\sum_{j=1}^{k} p_{i j} \ln p_{i j}\right) / \ln k\right] & \text { if } \max \left(p_{i j}\right)=p_{i 3}
\end{aligned}\right.
$$

with the superscript 'LA' indicating 'living arrangement'. The possible values of $C_{i}^{L A}$ lie in the range $[-1,1]$, where ' -1 ' stands for the dominance of traditional living arrangements, in particular of couples with children, while the value ' 1 ' represents regions dominated by modern living arrangements, particularly by single-person households. 1

Obviously these six demographic variables are only a selection of a broader spectrum of demographic characteristics. In particular, household size, number of children, and percentage of home owners are alternative demographic variables not included in this analysis. As these variables are highly correlated with those already included, our decision to skip them is justified. For instance, the average household size will be closely correlated with the form of living arrangements, while home ownership will be more prevalent in less densely settled areas and henceforth closely correlated to population density. Furthermore, the average age of the household head will be related to the labour force participation variable. 2

We assume that only four of the six variables will be directly connected to environmental behaviour. These are the average age, both disparity measures (employment status and living arrangements), and population density. The remaining two variables, population growth and educational level, are assumed to be exogenous to the model and to causally precede the other demographic variables. We expect regions with higher population growth rates are to be those with lower average ages. Positive population growth rates may not be caused by an increasing number of births but by higher in-migration numbers, but our argument is still valid since migrant populations are mainly composed of younger people. Population growth may also be positively related to the labour force participation and to the preponderance of modern living arrangements. Furthermore, we also expect regions with higher average educational levels to be characterised by more modern living arrangements. The link between average educational level and average labour force participation rate is dubious. In the long run one might expect regions with higher educational levels to have higher rates of labour force participation, but in the short run - and this might be more likely to be captured by our cross-sectional set up - regions with higher average educational levels may be those regions where a larger portion of the population is still in education and hence not yet in the labour force.

Concerning the direct demographic effects on environmental behaviour we consider the following four hypotheses:

\section{Population density hypothesis}

Population density is independent of individual characteristics and it more closely reflects the infrastructure of a region. We expect a negative relation between population density and the average distance driven in that region. On the other hand, we expect that a higher population density indicates regions with higher average fuel consumption since more inefficient 'styles of driving' are prevalent, which are caused by less fluent traffic, for instance. The overall effect is likely to be environmentalfriendly since in densely populated regions the intensity-decreasing effect often is more important than the efficiency-decreasing effect (cf. Newman and Kenworthy, 1988, 173).

1 The measure $\mathrm{C}_{i}^{\mathrm{LA}}$ is significantly correlated both to the share of modern living arrangements, that is single-person and single-parent households $(r=.883 ; p \leq .01)$, and to the share of living arrangements without children $(r=.829 ; p \leq .01)$.

2 Correlations are about: average household size to measure $C_{i}^{L A}(r=-.785 ; p \leq .01)$; share of home owners to population density $(r=-.584 ; p \leq .01)$; average age of the household head to the share of households with gainfully employed head ( $r=-$ $.802 ; p \leq .01)$ and to the share of gainfully employed people in a region $(r=-.366 ; p \leq .05)$. 
II. Life-cycle stage hypothesis

In order to investigate whether and to what extend the life cycle stage of the household head can be related to observed environmental behavior, we assume an association between regional averages of the age of household heads and car use intensity. The sign of the effect is indeterminate, as various explanatory models can be argued for. Assuming that car use first increases and then decreases with age would imply a parabolic association between these two variables, which in turn can lead to a non-significant causal effect when described with merely a linear function. Alternatively one can argue from a cohort perspective. Postulating that younger cohorts have grown up during years of an evolving awareness for the environment, car use should be more pronounced among older cohorts. Henceforth a positive association between these two variables should be observed.

\section{Gainful employment hypothesis}

Car use in each region will be closely linked to regional labor force patterns. The income effect and also possibly the necessity to commute to work would imply that those regions where 'being employed' is the dominant status should exhibit higher average car use.

\section{Living arrangement hypothesis}

We expect that the disparity of living arrangements and more precisely the preponderance of modern living arrangements of childless single-person households can be directly associated to car use in each region. Again, as in the case of the life-cycle stage hypothesis, the sign of the effect is not at all clear. It seems plausible that families have higher car use intensities since there are more tasks to be conducted that require a car, e.g., commuting to work, shopping, bring children to kindergarten, school, and various kinds of leisure-time activities (cf. Flade, 1999, Canzler, 2000). Hence, the dominance of modern living arrangements should imply reduced car use. On the other hand, it has been shown (cf. Eisner, Lamprecht and Stamm, 1993) that a significant number of trips with the car do not necessarily serve to fulfil specific tasks but are undertaken for leisure purposes, in particular by modern, young single persons. Henceforth the dominance of these living arrangements should be expected to increase car use intensity.

All three of these demographic variables are assumed to effect only the intensity and not the efficiency of car use. Their presumed effects on car use efficiency are mediated by car use intensity. Car use efficiency will be directly associated solely to car technology and regional infrastructures as represented by the population density variable.

\subsection{Direct control factor effects}

The fact that there is uncertainty concerning the sign of the direct effect coefficients of demographic variables on environmental behaviour means that further control factors should be included through which demographic structures may be transmitted. In addition to this mediating role, these control factors will also have a direct impact on car use.

\section{$V$. Attitudes-behaviour hypothesis}

Attitudes about environmental concerns constitute a preliminary stage of observed environmental action and should therefore be controlled for. Though this argument is based on a psychological pattern at the household level, it can nevertheless be measured on a regional level by referring to the percentage of households that own at least one car. ${ }^{1}$ Owning a car may not be a perfect indicator of lacking pro-environmental attitudes, but it is always a clear expression that one favours private motor vehicle-based mobility. Whether a higher percentage of households that own cars will effect the car use intensity positively or negatively cannot be answered a priori. More relevant in this regard will be the average number of cars per household in each region. Since only $74.5 \%$ of all households have indicated to own a car, we have - similarly to the case of the variables car use intensity and car use efficiency - applied a Heckman-type correction procedure to define the average number of cars per household. We expect that for those regions in which a higher percentage of households will have more than one car we will also observe higher car use intensities.

1 Alternative regional-level measures of environmental attitudes can be obtained from the Austrian micro-census as of December 1994 which included a special programme on the environment and environmental behaviour, the latter being measured in terms of consumer behaviour. In addition, participants had to rank various environment-related topics according to their perceived urgency (cf. Österreichisches Statistisches Zentralamt, 1995). This special programme was repeated in December 1998. 
An alternative set up would be to take car use intensity as the control factor that determines the average number of cars per household. Our set up is superior, however, since it allows us to first control for demographic factors. And these may effect the more long-term decision on the choice of how many cars households decide to own. A further argument for our set up is the fact that we are interested ultimately in explaining the environmental impact that can only be captured by measuring the actual use of car and not by the mere ownership of cars.

\section{Car technology hypothesis}

Differing technical features of cars may partially explain differences in observed car use intensity and car use efficiency. To control for car technology we define two measures that are available on the household level. These are the use of a catalytic converter and the type of motor technology.

To measure the degree of use of catalytic converters across the first two cars for each household we first define a dummy variable for each car indicating whether it is equipped with a catalytic converter $(=1)$ or not $(=0)$. Next we weight the dummy variables with the relative intensity of use per car and add these numbers to arrive at a continuous representation for the use of catalytic converters on the household level. We then derive NUTS-3 area-specific mean values by averaging over those households that run at least one car.

To construct the variable measuring the motor technology we have proceeded in an analogous way. For each car we weight the dummy variable that indicates the motor type for each car ( 0 for petrol and 1 for diesel engines) with per car intensities of use and add these values for each household. This gives a continuous variable measuring the degree of use of diesel engine across the first two cars at the household level with extreme values 0 (petrol engine only) and 1 (diesel engine only). NUTS-3 area-specific mean values have then been derived by averaging over those households that run at least one car.

We expect that the prevalence of a specific motor type will be related to both car use intensity and efficiency. In the case that diesel engines are dominant we expect a lower efficiency while we expect a higher intensity of car use. The first assumption captures the fact that diesel engines generally get better mileage, while the latter effect relates to the observation that households that use their car more intensively may opt for cars with diesel engines (Simhandl, 1998, 773). Though the last statement could indicate a reverse causality from car use intensity to the use of cars with diesel engines, one should keep in mind that we use the variable 'motor type' simply as a control variable for the dependent variable concerning car use intensity. We exclude any reverse causalities not just by the fact that we decided on the method of path analysis. Our data set up (being a cross-sectional survey) simply would not allow us to test for causality in household decision processes.

In addition, we wish to determine whether and to what degree the use of catalytic converters might be related to car use intensity and/or efficiency. Though catalytic converters are mandatory for all cars registered after 1987, we can nevertheless relate the dominance of use of catalytic converters to attitudes towards the environment since about $47.5 \%$ of all cars (and $24.5 \%$ of cars equipped with petrol engines, cf. Simhandl, 1998, 772) have not yet been affected by these regulations. It is then of primary interest to verify whether the use of catalytic converters will translate into lower car use intensities or whether these pro-environmental attitudes are neutralised by higher intensities of car use.

\section{Structural constraint hypothesis}

The third block of control variables includes two variables that capture regional prosperity and regional levels of work-related commuting between regions. The latter variable in particular is expected to have a pronounced effect on car use intensity since work-related commuting is often conducted with one's own car (Brüderl and Preisendörfer, 1995).

Regional prosperity is measured by per capita income as available on the NUTS-3 level by Statistics Austria. This measure is to be preferred to mean household income levels since the latter are closely related to the mean household size and the various types of family arrangements in a region.

To approximate work-related commuting we define a net commuting index for each region, which relates the number of gainfully employed people at their home to the number of gainfully employed people at their working place. This ratio becomes greater than one whenever a region cannot provide as many jobs as gainfully employed people are living in that region. In that case, at least part of the gainfully employed people will leave (possibly on a regular, daily basis) a region in order to get to 
working places in other regions. ${ }^{1}$ This should then be regarded as an important explanatory factor that raises car use intensity.

\subsection{Mediated (indirect) demographic effects}

Both car use intensity and efficiency may not be related only to demographic structure and various control factors. The paths may be more complicated, as control factors may themselves be closely connected to the demographic structure. It is necessary to include these indirect effects since the variables considered are only snapshots of underlying dynamic processes that may follow different paces. One might therefore expect that part of the demographic structure is mediated through the control factors and indirect effects may even neutralise the direct impact of demographic structures.

Taking the demographic structure and the three groups of control factors as four distinct components that can effect environmental behaviour either alone or in combination of two or more components, one can (by referring to some basic combinatorial analysis) consider $\left(\begin{array}{l}4 \\ 1\end{array}\right)=4$ direct effects, $\left(\begin{array}{l}4 \\ 2\end{array}\right)=6$ combined effects that include always two components, $\left(\begin{array}{l}4 \\ 3\end{array}\right)=4$ combined effects with three components each, or in the extreme $\left(\begin{array}{l}4 \\ 4\end{array}\right)=1$ combined effect including all four components. A model that included all possible effect combinations would only add to the complexity without providing a better understanding of reality. Since we only focus on indirect effects of demographic structures as mediated by the remaining three groups of control factors, we are excluding some of the effect combinations from the outset. Among the remaining eleven effect combinations, we focus on four indirect effects only.

\section{Interaction of demography and attitudes}

We expect demographic structures to shape the fundamental attitudes towards car use (as measured by the share of car users) and the extend of preconditions to car use (as measured by the number of cars per household). As both of the latter variables will determine car use intensity, these variables act as mediator variables for demographic structures. It is most likely that this indirect influence is more important than a direct demographic impact on environmental behaviour.

IX. Interaction of demography and structural constraints

As in the previous hypothesis, we expect demographic structures to determine regional measures of prosperity and net commuting - and that these variables will thus act as a mediator between demographic structures and observed environmental behaviour.

$X$. Interaction of demography, structural constraints, and attitudes

Since the prevalence of net commuting may effect attitudes towards car use, we introduce a sequential interaction path. Demographic structures may be related to the structural constraints in a region, which in turn will have an impact on attitudes and, consequently, on observed environmental behaviour. In addition to the demographic structures discussed so far, we expect the average educational level in a given region to be positively related to the average per capita income level in that region.

$X I$. Interaction of demography, structural constraints, and car technology

As in the previous hypothesis, we allow for a sequential interaction path that relates demographic structure to regional institutional factors. The latter will effect environmental behaviour as mediated through the choice of car technology. In particular, regions with higher net commuting index may be those where diesel engines are dominant, since diesel-powered cars are cheaper if intensively used. This is the only path where we postulate car technology to act as a mediating variable. We have not considered any interaction between demographic structure and car technology, since the latter set of variables will most likely not be influenced by demographic structure directly but to be determined instead by institutional factors, price patterns, or specific tax incentives.

\section{PATH ANALYSIS}

\subsection{Methodological remarks}

Since demographic factors will directly as well as indirectly (as transmitted by control factors) be related to the average car use intensity and car use efficiency in each region, our model can be imple-

\footnotetext{
1 Of course, even if the net commuting index is less than one there may be a positive level of work-related commuting.
} 
mented by a set of interdependent equations. Altogether the model includes 10 equations (Table 2), with the following set of dependent variables defined for each NUTS-3 area: the average age of household heads $(A)$; concentration index of employment status $(B)$, concentration index of living arrangements $(C)$, per capita income $(D)$, net commuting index $(E)$, share of households with cars $(F)$, average number of cars per household $(G)$, use of diesel engines $(H)$, car use intensity $(I)$, car use efficiency (J). The remaining four variables (average educational level, population growth, population density, and use of catalytic converters) are assumed to be exogenous to the causal model.

The specific design of an interdependent system of equations with a given causal structure allows us to conduct a path analysis, i.e. it allows for the decomposition of bivariate correlations between measures of demographic structure and measures of environmental behaviour into direct and indirect effects. As compared to a single-equation estimation for either car use intensity or car use efficiency, within path analysis causal interrelationships between control factors can be controlled for. In this particular framework path analysis is favoured to the latent-structure oriented LISREL-approach (Jagodzinski, 1986) as it allows us to assess the postulated effects between all variables of the model. Given this recursive system, and assuming that the error terms of these 10 equations are uncorrelated with each other, we can apply OLS for each equation separately (cf. Greene, 1993, 600). The resulting path coefficients are then equivalent to the standardized estimates of the OLS regression. Since the standardized effects are dimensionless the path coefficients represent proportional effects.

\begin{tabular}{|c|c|c|c|c|c|c|c|c|c|c|}
\hline & \multicolumn{3}{|c|}{ DEMOGRAPHIC STRUCTURE } & \multicolumn{2}{|c|}{ CONSTRAINTS } & \multirow[b]{2}{*}{$\begin{array}{c}\text { TECHNOLOGY } \\
\text { (F) } \\
\text { Cars with } \\
\text { diesel } \\
\text { engine }\end{array}$} & \multicolumn{2}{|c|}{ MOBILITY-ATTITUDES } & \multicolumn{2}{|c|}{ ENV. BEHAVIOUR } \\
\hline & $\begin{array}{c}\text { (A) } \\
\varnothing \text { Age } \\
\text { of } \\
\text { HH-heads }\end{array}$ & $\begin{array}{l}\text { (B) } \\
\text { Conc. of } \\
\text { empl. } \\
\text { status }\end{array}$ & $\begin{array}{l}\text { (C) } \\
\text { Conc. of } \\
\text { living arr. }\end{array}$ & $\begin{array}{c}\text { (D) } \\
\text { Per capita } \\
\text { income }\end{array}$ & $\begin{array}{c}\text { (E) } \\
\text { Net } \\
\text { commuter- } \\
\text { index }\end{array}$ & & $\begin{array}{c}\text { (G) } \\
\text { \% of } \mathrm{HHs} \\
\text { with } \operatorname{car}(\mathbf{s})\end{array}$ & $\begin{array}{c}(\mathrm{H}) \\
\varnothing \mathrm{No.} \text { of } \\
\text { cars } \\
\text { per HH }\end{array}$ & $\begin{array}{c}\text { (I) } \\
\varnothing \\
\text { Distances }\end{array}$ & $\begin{array}{c}(\mathrm{J}) \\
\varnothing \text { Fuel } \\
\text { consump- } \\
\text { tion }\end{array}$ \\
\hline $\begin{array}{c}\varnothing \text { Educational } \\
\text { level }\end{array}$ & & $\begin{array}{l}-.804^{\star \star \star} \\
-.678^{\star \star \star}\end{array}$ & $\begin{array}{l}.864^{\star \star \star *} \\
.743^{\star \star \star}\end{array}$ & $\begin{array}{l}.634^{\star \star \star} \\
.800^{\star \star *}\end{array}$ & & & & & & \\
\hline $\begin{array}{l}\text { Population } \\
\text { growth }\end{array}$ & $\begin{array}{l}-.479^{\star \star \star \star} \\
-.479^{\star \star \star}\end{array}$ & $\begin{array}{l}.374^{\star \star \star \star} \\
.102\end{array}$ & $\begin{array}{l}-.358^{\star \star \star \star} \\
-.066\end{array}$ & & & & & & & \\
\hline $\begin{array}{l}\text { Population } \\
\text { density }\end{array}$ & & & & $\begin{array}{l}.203^{\star} \\
.558^{\star \star \star}\end{array}$ & & $\begin{array}{l}-.211 \\
-.322^{\star}\end{array}$ & $\begin{array}{l}-.411^{\star \star \star} \\
-.631^{\star \star \star}\end{array}$ & $\begin{array}{r}.186 \\
-.051\end{array}$ & $\begin{array}{l}-.037 \\
-.227\end{array}$ & $\begin{array}{l}.072^{\star} \\
-.127\end{array}$ \\
\hline $\begin{array}{c}\varnothing \text { Age of } \\
\text { HH-heads }\end{array}$ & & & & $\begin{array}{l}-.253^{\star \star} \\
-.432^{\star \star *}\end{array}$ & & & $\begin{array}{l}.379^{\star \star \star} \\
-.257_{+}\end{array}$ & $\begin{array}{l}.542^{\star \star \star} \\
.589^{\star \star *}\end{array}$ & $\begin{array}{l}-.073 \\
.413^{\star \star}\end{array}$ & \\
\hline $\begin{array}{l}\text { Conc. of empl. } \\
\text { status }\end{array}$ & & & & $\begin{array}{l}-.023 \\
-.518^{\star \star *}\end{array}$ & $\begin{array}{l}.233^{\star \star} \\
.595^{\star \star \star}\end{array}$ & & $\begin{array}{l}.226 \\
.719^{\star \star \star}\end{array}$ & $\begin{array}{l}.278 \\
.200\end{array}$ & $\begin{array}{l}-.386^{\star \star} \\
.206\end{array}$ & \\
\hline $\begin{array}{l}\text { Conc. of living } \\
\text { arrangements }\end{array}$ & & & & $\begin{array}{l}-.015 \\
.614^{\star \star \star}\end{array}$ & & & $\begin{array}{l}-.285^{\star} \\
-.644^{\star \star \star}\end{array}$ & $\begin{array}{r}.263 \\
-.227\end{array}$ & $\begin{array}{r}.131 \\
-.228 \\
-2\end{array}$ & \\
\hline Per capita income & & & & & $\begin{array}{l}-.699^{\star \star \star \star} \\
-.820^{\star \star \star}\end{array}$ & & & & & \\
\hline $\begin{array}{l}\text { Net commuter- } \\
\text { index }\end{array}$ & & & & & & $\begin{array}{l}.348^{\star \star} \\
.422^{* \star}\end{array}$ & $\begin{array}{l}.091 \\
.433^{* *}\end{array}$ & $\begin{array}{l}.421^{\star \star} \\
.529^{\star \star \star}\end{array}$ & $\begin{array}{l}.254+ \\
.528^{\star \star \star}\end{array}$ & \\
\hline $\begin{array}{c}\text { Cars with catalytic } \\
\text { converter }\end{array}$ & & & & & & & & & $\begin{array}{l}-.285^{\star \star \star} \\
.248\end{array}$ & \\
\hline $\begin{array}{c}\text { Cars with diesel } \\
\text { engine }\end{array}$ & & & & & & & & & $\begin{array}{l}.240^{\star \star} \\
.507^{* * *}\end{array}$ & $\begin{array}{l}-.115^{\star *} \\
.387^{* *}\end{array}$ \\
\hline $\begin{array}{l}\% \text { of } \mathrm{HHs} \\
\text { with cars }\end{array}$ & & & & & & & & & $\begin{array}{l}.450^{\star \star \star} \\
.187\end{array}$ & \\
\hline $\begin{array}{l}\varnothing \text { No. of cars } \\
\text { per HH }\end{array}$ & & & & & & & & & $\begin{array}{l}.879^{\star \star \star \star} \\
.779^{\star \star \star}\end{array}$ & \\
\hline$\varnothing$ Distances & & & & & & & & & & $\begin{array}{r}1.041^{\star \star \star \star} \\
.967^{\star \star \star}\end{array}$ \\
\hline $\mathbf{R}^{2}$ & .230 & .583 & .666 & .733 & .712 & .217 & .742 & .529 & .823 & .953 \\
\hline $\mathbf{R}_{\text {adj. }}^{2}$ & .206 & .557 & .645 & .687 & .694 & .168 & .697 & .447 & .759 & .948 \\
\hline
\end{tabular}

Tab. 2: Bivariate Pearson correlation coefficients (in italics) and OLS estimates of path coefficients (bold). Significance levels are denoted with ${ }^{+}(p \leq .15),{ }^{*}(p \leq .10) ;{ }^{* \star}(p \leq .05) ;{ }^{* \star *}(p \leq .01)$.

Source: Authors own calculations, based on the Austrian micro-census as of June 1997.

\subsection{Goodness of Fit}

For the assessment of the causal relations it is crucial to determine how well the system of equations can explain the variation in the data. The goodness of fit of the whole model can be judged in three ways:

(a) We can verify the goodness of fit of each single equation for the set of 10 equations of the overall path model. In 8 out of 10 equations an $\mathrm{R}^{2}$ greater than .5 can be achieved. On average, the set of chosen regressors can explain the inter-regional variation of the endogenous variables to a large extent. The equations for car use intensity and car use efficiency yield an $R^{2}$ of .823 and .953 respec- 
tively. But also the share of households with cars and the regional income levels can be explained to a high degree within our proposed framework as evidenced by an $\mathrm{R}^{2}$ of .742 and .733 . Within the set of four variables that represent attitudes toward environmental behaviour and environmental behaviour itself, only one variable, the average number of cars per household is a little less well explained as indicated by a $R^{2}$ of .529 . The fact that some endogenous variables such as the average age or the percentage of cars with diesel engine are not explained very well by our set up is not surprising, since the model may not incorporate all relevant factors for these variables to be explained. Our aim is to explain environmental behaviour and not necessarily also regional variations in factors determining environmental behaviour, so the the non-optimal fit for these other variables is partly irrelevant.

\begin{tabular}{|c|c|c|c|c|c|c|}
\hline$\varnothing$ Distances & $\begin{array}{c}(1) \\
\varnothing \\
\begin{array}{c}\text { Educational } \\
\text { level }\end{array}\end{array}$ & $\begin{array}{c}\text { (2) } \\
\text { Population } \\
\text { growth }\end{array}$ & $\begin{array}{c}\text { (3) } \\
\text { Population } \\
\text { density }\end{array}$ & $\begin{array}{c}\text { (A) } \\
\varnothing \text { Age } \\
\text { of } \\
\text { HH-heads }\end{array}$ & $\begin{array}{l}\text { (B) } \\
\text { Conc. of } \\
\text { empl. } \\
\text { status }\end{array}$ & $\begin{array}{c}\text { (C) } \\
\text { Conc. of } \\
\text { living arr. }\end{array}$ \\
\hline $\begin{array}{l}\text { Pearson's } r \\
\text { direct effect }\end{array}$ & -.302 & -.309 & $\begin{array}{l}-.227 \\
-.037\end{array}$ & $\begin{array}{r}.413 \\
-.073\end{array}$ & $\begin{array}{r}.206 \\
-.386\end{array}$ & $\begin{array}{r}.228 \\
.131\end{array}$ \\
\hline indirect effect & -.241 & -.207 & -.178 & .438 & .533 & .111 \\
\hline total causal effect & -.241 & -.207 & -.215 & .365 & .147 & .242 \\
\hline non-causal effect & -.061 & -.102 & -.012 & .048 & .059 & -.470 \\
\hline
\end{tabular}

\begin{tabular}{|c|c|c|c|c|c|c|}
\hline \multicolumn{7}{|l|}{$\varnothing$ Fuel consumption } \\
\hline $\begin{array}{l}\text { Pearson's } r \\
\text { direct effect }\end{array}$ & -.208 & -.275 & $\begin{array}{r}-.126 \\
.072\end{array}$ & .360 & .141 & -.172 \\
\hline indirect effect & -.250 & -.212 & -.194 & .373 & .154 & .252 \\
\hline total causal effect & -.250 & -.212 & -.122 & .373 & .154 & .252 \\
\hline non-causal effect & .042 & -.063 & -.004 & -.013 & -.013 & -.424 \\
\hline
\end{tabular}

Tab. 3: Decomposition of bivariate correlations between measures of demographic structure and measures of environmental behaviour.

Source: Authors own calculations, based on the Austrian micro-census as of June 1997.

(b) The second way to assess the appropriateness of our proposed model involves the possibility of decomposing the empirical bivariate correlations into direct and indirect causal effects (see Table 3). Since the causal structure is not completely specified part of the resulting effects between two variables may be due to indirect effects that are not causally motivated. Considering the 12 relevant bivariate correlations between measures of demographic structure and measures of environmental behaviour, in 10 cases we find non-causal effects that are either partly of relevance or even of only marginal importance. Only in 2 cases the non-causal impact is predominant.

(c) A third way to verify the appropriateness of our model set up involves the correlation matrix of the error terms of all 10 equations. Applying a log-likelihood-ratio test the basic assumption of uncorrelated errors due to the recursive nature of the system cannot be rejected. ${ }^{1}$ Therefore the statistical prerequisite for conducting a path analysis is valid.

\section{DETERMINING MECHANISMS OF REGIONAL LEVEL CAR USE}

\subsection{Direct demographic impacts with and without controlling for other variables}

Together, the four demographic factors (population density, age, concentration of employment status and concentration of living arrangements) can only capture a small part of the interregional variance of average distances driven $\left(\mathrm{R}^{2}=.235\right)$. The inclusion of variables related to car technology, economic structural constraints and attitudes towards car use (ownership and number of cars) improves the explanatory power of the model as evidenced in Table 2, equation $I$. It seems that only the hypothesis on gainful employment is supported by the regression results whereas all other demographic hypotheses have to be rejected.

In case of the car use efficiency (as measured by the fuel consumption) we obtain the postulated efficiency decreasing direct effect of population density. In densely populated regions fuel consumption per household is significantly higher, even after controlling for motor technology. 2

\subsection{The impact of non-demographic factors}

In contrast to demographic factors, control variables exhibit highly significant coefficients in the regression of car use intensity. A high level of commuting to neighbouring regions raises the intensity of car use. The positive sign for the net commuting index confirms the structural constraint hypothesis (VII.). Similarly, the share of car owners within a region and the number of cars per household increase car use intensity as described in the attitudes-behaviour hypothesis $(V$.). The former result

1 The test statistic $-2 \ln \lambda=\mathrm{N}\left[\ln\right.$ Det $\left.\sum_{\mathrm{Ho}_{0}}-\ln \sum_{\mathrm{H} 1}\right] \approx \chi 2(\# \mathrm{df})$ is equal to 30.126 with df 45 .

2 The aggregate fuel consumption in these regions may well be smaller since fewer households own cars. 
seems obvious, but the latter result is surprising. Not only are these regions in which households have above average car ownership, but they are also regions where cars are used more intensively. In a regression of car use efficiency (equation $J$ in Table 2), an increase in car use intensity leads to a decrease in efficiency. The estimated path coefficient of 1.041 shows that this environment-degrading impact is more than proportional. The use of cars with diesel engines raises both car use intensity and efficiency significantly. These results confirm the postulated car technology hypothesis (VI.). Taken together, the effect mediated by car use intensity $(.240 \times 1.041=.250)$ dominates the direct effect of -.115 . Consequently, the net effect on car use efficiency is positive (.135), which implies potential harm for the environment.

An reverse - and thus environmental beneficial - effect is transmitted by the use of catalytic converters. It is not just the case that the use of catalytic converters itself reduces the amount of emissions. In those regions where the use of catalytic converters is more prevalent, car use intensity is lower and hence less fuel is consumed.

Obviously, in a single-equation approach non-demographic factors do explain varying car use intensities much better than measures of demographic structure do. But, by applying the concept of path analysis it can be shown that effects of demographic variables are mainly mediated by these non-demographic control factors (see the causal diagram with path estimations in Figure 5).

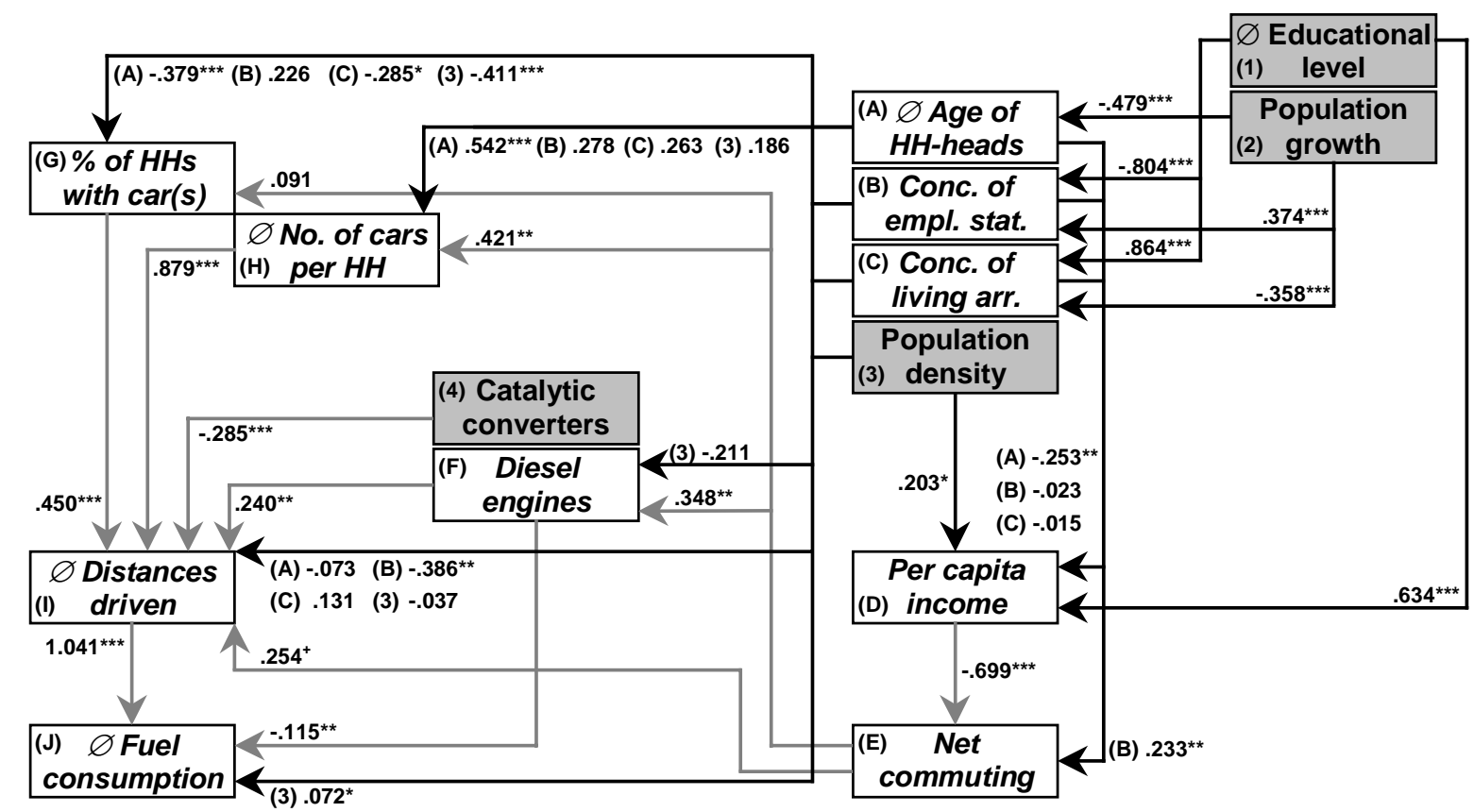

Fig. 5: Estimated path coefficients of causal structure of interrelationships among the factors population, technology, institutional factors, and environmental behaviour. Grey boxes containing exogenous variables, causal control factor effects are marked with grey arrows. Significance levels are denoted with ${ }^{+}(p \leq .15),{ }^{*}(p \leq .10) ;{ }^{* *}(p \leq .05) ;{ }^{* \star *}(p \leq .01)$.

Source: Authors own calculations, based on the Austrian micro-census as of June 1997.

\subsection{Effects of the mean age}

The original correlation of .413 between the mean age of household heads and the average distance driven in each region can almost entirely be explained by indirect effects as mediated through the group of control variables.

Age largely explains the prerequisite of private car mobility such as car ownership and the number of cars per household. A growing mean age reduces the share of car owners but raises the average number of cars per household. Combined with the positive effect of the prerequisite of private car mobility on car use intensity, a growing mean age also decreases car use intensity via the share of car owners $(-.379 \times .450=-.171)$, but increases it through the number of cars per household $(.542 \times$ $.879=.476)$. Adding the effects of both inter-mediating variables $(-.171+.476=.305)$ indicates an overall negative environmental impact for regions with higher average ages of the household head since the intensity of car use is higher there. 
The fact that age is negatively related to the percentage of households with cars but positively related to the number of cars per household can be explained as follows. In those regions where the average age of household heads is higher, the share of retired people is larger $(r=.890)$ and these are the regions where fewer households own a car $(r=-.338)$. For the remaining households in these regions, where the household head is not yet retired, it can be argued that a 'cumulative' process of the durable consumption good 'car' takes place, the reason being that demand for more than one car increases over the life-cycle course. For instance, there could be a second car for the wife of the household head and a third car for children still living in the household.

A further environmentally detrimental effect of age operates through structural economic constraints. Regions with a higher average age of household heads are those with lower per capita income and consequently high net commuting into neighbouring regions. The overall effect on car use intensity is therefore positive $(-.253 \times-.699 \times .254=.045)$. Additionally, in those regions that are characterised by high net commuting, the number of cars per household is higher and the detrimental environmental impact is further strengthened $(-.253 \times-.699 \times .421 \times .879=.065)$. The result seems plausible since households that are subject to higher commuting need to ensure the mobility for the remaining household members by having a second or third car.

Connected with higher values on the net commuting index is also the increased ownership of cars with diesel engines in these regions and a higher value for car use intensity. The resulting path is again environmentally detrimental $(-.253 \times-.699 \times .348 \times .240=.015)$. The results are highly plausible since diesel engines are most economically used when used very intensively due to lower average fuel consumption and the lower price of diesel fuel.

Comparing the various paths along which the age variable effects car use intensity we can conclude that age has almost no direct impact, while the indirect effects are predominately environmentally detrimental. Car use intensity increases in relation to lower regional economic well being and higher commuting, and age has the strongest effect on the pre-conditions for a negative environmental impact such as car ownership and the number of cars per household. Adding up the causal effects across the paths, we have an effect coefficient of .365 (including the direct effect of -.073). This means that there remains a non-causal part of the bivariate correlation between mean age and average car use intensity of .048 (see Table 3).

The effect of age on car use efficiency is (with only one exception) identical to the effect on car use intensity, since almost all effects are mediated through car use intensity by design of the equations system. The indirect effects sum up to .373 including the environmentally favourable combination of commuting and use of diesel engines, which implies greater car use efficiency $(-.253 \times-.699 \times .348 \times$ $-.115=-.007)$. Compared to the original correlation of .360 the combined effects leave an unexplained part of only -.013 (see Table 3). This means that the bivariate correlation between mean age and car use efficiency can be explained very well by the causal structure assumed in our model.

\subsection{Effects of regional distributions of employment status and living arrangements}

Contrary to the regional age structure, most effects of the concentration of living arrangements and the concentration of employment status on car use intensity and efficiency are not significant. But, the preponderance of the employment status 'gainfully employed' directly reduces the car use intensity. Also, the share of car owners is significantly reduced by distribution of living arrangments as far as modern living arrangements are predominant within a region. This in turn decreases also car use intensity because of the intensity-raising effect of the share of car owners $(-.285 \times .450=-.128)$. Besides this impact, environmental behaviour is largely independent of the regional distribution of living arrangements. This fact is highlighted in Figure 6, which has been set up to obtain characteristic combinations out of the variables average age, living arrangement and car use intensity. We have built up five types, with two types being defined as having either the regional average age and the regional average car use intensity above or below the national average level of these variables. Starting from these two types we further distinguish whether modern or traditional living arrangements are predominant in each region. This provides four different types of possible combinations which can explain the characteristics of 27 out of 35 NUTS-3 areas. For the remaining 8 regions where the average age and the average car use intensity do not simultaneously exceed or fall below the national average, we have defined a fifth category. 


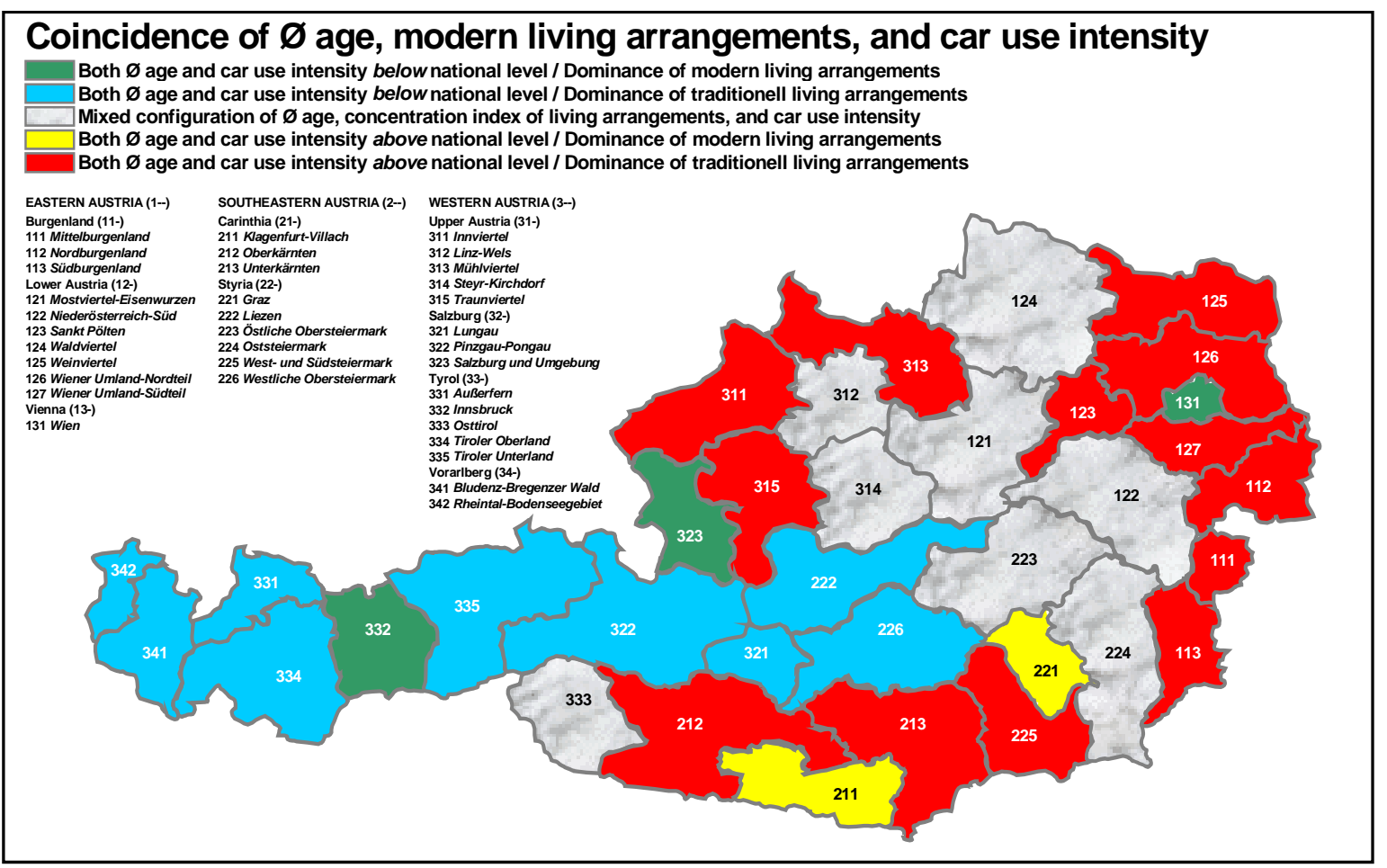

Fig. 6: Spatial pattern of coincidence of $\varnothing$ age, modern living arrangements, and car use intensity.

Source: Authors own calculations, based on the Austrian micro-census as of June 1997 with NUTS-3 pattern taken from Österreichisches Statistisches Zentralamt, 1996.

The regional distribution of these five types is obvious: Independently of the prevailing living arrangements, 'young' regions with low car use intensity are concentrated in Western and Central Austria. 'Older' regions with high car use intensity are concentrated in the North, North-East, East and South of Austria. Again, the form of the living arrangement does not lead to further differences between these regions. Only the urban regions of Graz (221) and Klagenfurt-Villach (211) stand out as being characterised by the dominance of modern living arrangements. Surprisingly, the fifth type is regionally strongly clustered (with Osttirol (333) as an exception). This type is most prevalent in Eastern Austria and extends along a North-South band. In summary, Figure 6 highlights once more the importance of the average age of the household head in each region (as opposed to the index of living arrangement) in explaining the average regional car use intensity.

\subsection{Effects of population density and population growth}

Population density is a central demographic measure that acts as an indicator for the spatial extension of households in each region. While population density does not have the expected direct impact on the intensity of car use, it has a direct positive effect on fuel consumption.

The bivariate correlation between population density and car use intensity $(r=-.227)$ can be decomposed into causal and non-causal effects, the latter being of only marginal importance (-.010) (see Table 3). Population density indirectly reduces the car use intensity by reducing the percentage of households with cars in each region $(-.411 \times .450=-.185)$. It can be argued that shorter distances and better public transportation make it easier for households to refrain from using a car. On the other hand, a positive although not significant effect on the average number of cars per household is evident. Multiplied with the positive path coefficient that relates the average number of cars with car use intensity, this means that population density has the effect of increasing car use intensity $(.186 \times .879$ $=.163$ ). Obviously, this could indicate an antagonism of different car use patterns within highly urbanized areas. There are fewer households than in rural areas that own cars, but those that decide to do so, typically own more than one private car. This sort of behaviour presumably reflects the fact that even within agglomerations, many households need to coordinate their spatially separated daily life activities, which can most easily be archived by taking private cars (cf. Canzler, 2000).

The effect of population density on the use of cars with diesel engines is not significant. Nevertheless the sign of this effect is as expected, and it is supported by including per capita income and commuting as additional variables. Densely populated regions can be associated with higher per capita in- 
come levels, particularly regions with a dominant tertiary sector, which pays higher wages than the agricultural and industrial sectors. ${ }^{1}$ Hence in densely populated and 'wealthy' regions, net commuting is lower and consequently the use of cars with diesel engines is less prevalent $(.203 \times-.699 \times .348 \times$ $.240=-.012)$. In summary, the population density has a significant negative effect on the use of cars with diesel engines and consequently reduces the car use intensity. The effect works, however, through the mediating factors of per capita income and net commuting.

The rate of population growth constitutes a demographic variable that is often connected with a negative environmental impact in developing countries. But as shown by Cramer (1998) for California the role of population growth as induced by migration flows may have a considerable impact on the environment in developed countries as well. Though not as pronounced as in the study by Cramer, the rates of population growth and decline in Austria are at least sufficiently evident so as to justify a more in-depth consideration of population growth rates. Between 1981 and 1991 the population of all NUTS-3 areas grew by $3.3 \%$ on average. The largest population decline, which was in the order of $6.2 \%$, could be observed in region 223 (Östliche Obersteiermark), while regions 126 (Wiener Umland-Nordteil) and 323 (Salzburg) recorded the largest increase, with $11.02 \%$ and $10.44 \%$ respectively. The non-significant correlation $(r=-0.077)$ between population growth $81 / 91$ and population density as of 1981 indicates that there did not exist any clear-cut pattern of population growth. This means that it is neither that only the urban centres were subject to growth nor did a pronounced migration to the countryside take place. Nevertheless, a geographic pattern does emerge: the regions that experienced population decline are located in the East.

Car use intensity (and car use efficiency) is only affected by population growth through region specific demographic variables. From the proposed model two consequences of population growth for environmental behaviour can be drawn: (a) Since the average age of the household head has been discerned as the key variable, population growth will mainly effect regional environmental behaviour as mediated by the average age of the household head. Consequently all environmentally detrimental direct and indirect effects of the age structure on the intensity of car use will change into environmental beneficial effects, mediated through population growth. An essential explanatory reasoning for the observed East-West difference in car use intensity is thereby provided, since NUTS-3 areas in Western Austria have a growing population, which reduces the average age. (b) Predominance of traditional living arrangements is more likely in regions with a growing population. Therefore population growth implies increases in both car use intensity and efficiency because the preponderance of a more traditional family structure raises the share of car owners in a region which automatically means a higher car use intensity $(-.358 \times-.285 \times .450=.046)$.

\subsection{Effects of mean educational level}

Like population growth, educational level is a background variable, which works only through structural demographic variables such as the employment status and living arrangements and by virtue of the fact it has an additional effect on per capita income. Regions with higher average educational levels for the household head are characterised by more modern living arrangements, which implies a lower share of households with cars and consequently lower levels of car use intensity. The main effect of the educational level is that it is positively related to per capita income, which implies less net commuting and fewer cars per household, as well as less use of cars with diesel engines $(.634 \mathrm{x}$ $.699 \times .254=-.113$ and $.634 \times-.699 \times .348 \times .240)$. Across these paths, the educational level only has an environmentally beneficial impact because it reduces car use intensity and car use efficiency.

\subsection{Interaction of affluence, commuting activities, engine technology, and car use}

To stress that region-specific variables play a very important role as factors mediating the effects of demographic characteristics Figure 7 presents the regional distribution of the interaction of affluence, commuting, use of cars with diesel engines, and car use intensity. These various characteristics are summed up in order to contrast two 'ideal types' with a more 'mixed category'. The combination of per capita income above the national level, a net commuter index smaller than one, and both degree of diesel engine use and car use intensity below national average can be viewed as characteristic for urban regions that function as regional centres. On the other hand, the type 'rural region at the periphery of central regions' is characterised by exactly the opposite: low per capita income levels, net

\footnotetext{
1 The correlation between population density and the percentage of people employed in the tertiary sector equals .408 .
} 
commuter index greater than one, high percentage of cars with diesel engines, and car use intensity above national average. In the third category we group all remaining 18 regions that cannot be assigned to either of the other categories.

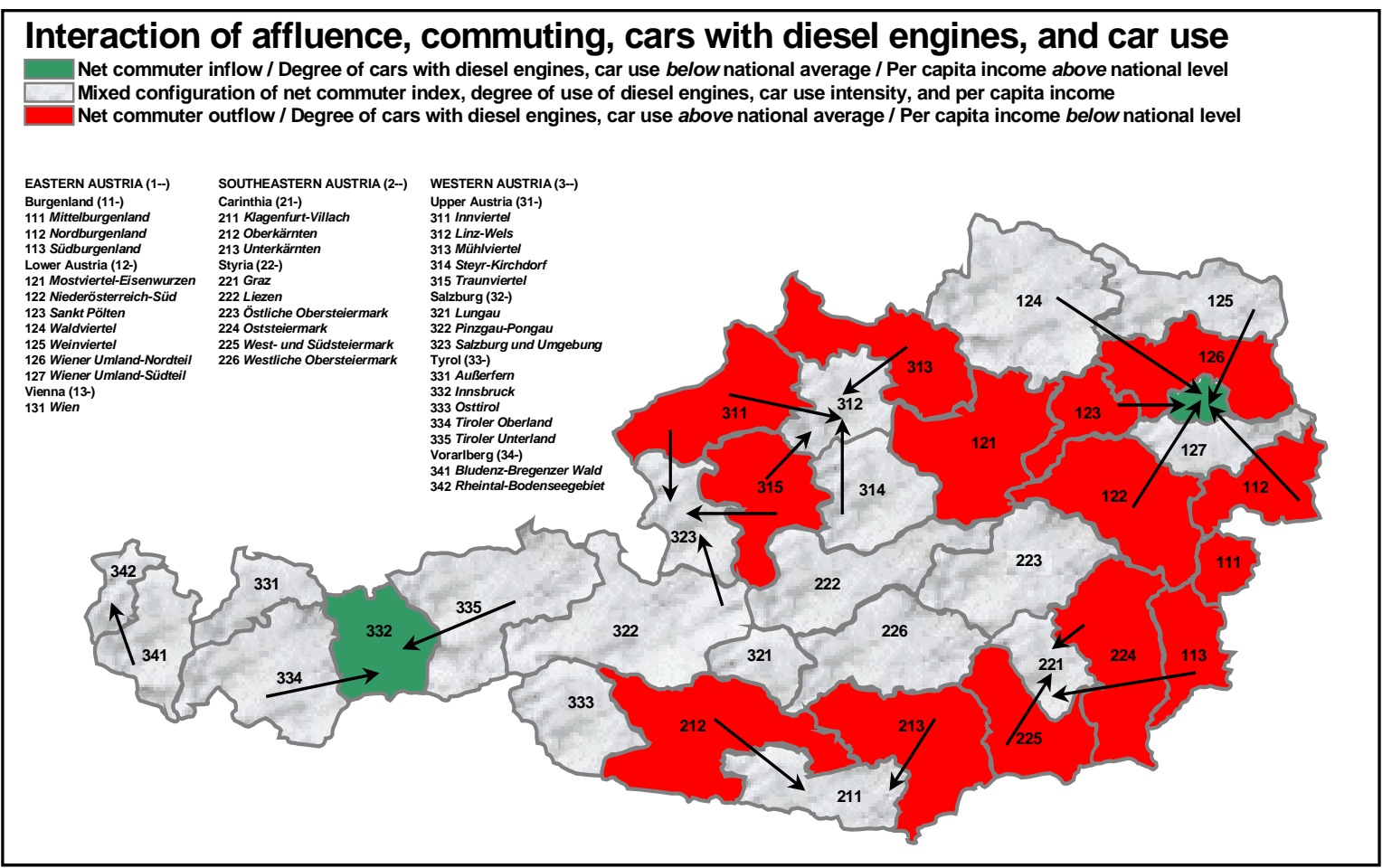

Fig. 7: Spatial pattern of interactions between affluence, commuting, cars with diesel engines, and car use.

Source: Authors own calculations, based on the Austrian micro-census as of June 1997 with NUTS-3 pattern taken from Österreichisches Statistisches Zentralamt, 1996.

Again, a regional clustering is to be observed for the second type. These rural regions are located exclusively in the vicinity of urban centres in the East (Vienna), North (Linz-Wels), and South/South East (Klagenfurt-Villach and Graz). We have also indicated the net commuter flows in Figure 7. We have refrained from indicating any commuting across the national borders, though these may well be a significant factor. For instance, the NUTS-3 area 342 (Rheintal-Bodenseegebiet) is characterised by a net commuter index of 1.1076 , indicating that there are about $11 \%$ more household heads that are employed than the number of employed people living in this region. Obviously, commuting to the neighbouring countries of Germany (districts of Lindau and Friedrichshafen) and Switzerland (cantons St. Gallen, Appenzell and Graubünden) is very pronounced in this particular region.

\section{CONCLUSIONS}

Private car use is one of the major causes of $\mathrm{CO}_{2}$ emissions in developed countries. For this reason, it has become important for various scientific disciplines to conduct research that will lead to an understanding of the determinants of private car use. While economics has mainly focused on institutional factors, technological pre-conditions, and price mechanisms, the sociology literature focuses on the individual decision process.

Though a combination of both micro and macro level determinants would be the preferred solution, data limitation often imposes strong restrictions on the methodology that can be used. In this study we have attempted to solve the compromise between data availability and research design by setting up a multi-dimensional model of car use on the regional level. The aim of our study is to explain regional differences in car use by regional differences in various control factors, with a special emphasis on the role of the demographic structure of each region.

In contrast to the well known I-PAT identity, which only provides a decomposition of a detrimental environmental impact into its various constituent components, we propose a theoretically motivated causal structure between the control factors. This set up allows us to decompose the correlation between private car use and any of its proposed determinants into direct and indirect effects. In addition, we can distinguish causal and non-causal components of the correlation. 
The empirical validation of our model within a static analysis ${ }^{1}$ provides evidence that demographic structures cannot be linked directly to private car use intensities on a regional level. In contrast, determinants that can be directly linked to private car use are region-specific institutional factors, regional differences in measures of car technology and region-specific attitudes towards car use. However, regional demographic characteristics are causally linked to private car use if we permit control factors to function as mediating variables. For instance, the average age of household heads in a region turns out to be an important indicator for several of the other control factors, such as, e.g., the share of households with cars, the average number of cars per household and region-specific per capita income levels. The validity of our results is further strengthened by the match between the regional pattern of car use intensity and various combinations of control factors.

\section{REFERENCES}

Bailey KD. 1990. From POET to PISTOL: Reflections on the Ecological Complex. Sociological Inquiry 60: 387394.

Black JS, Stern PC and Elworth JT. 1985. Personal and contextual influences on household energy adaptations. Journal of Applied Psychology 70(1): 3-21.

Brüderl J, Preisendörfer P. 1995. Der Weg zum Arbeitsplatz: Eine empirische Untersuchung der Verkehrsmittelwahl. In Kooperatives Umwelthandeln. Modelle, Erfahrungen, Massnahmen, Diekmann A, Franzen A (eds); Chur/Zürich; 69-88.

Canzler W. 2000. Das Auto im Kopf und vor der Haustür. Zur Wechselbeziehung von Individualisierung und Autonutzung. Soziale Welt 51: 191-208.

Canzler W, Knie A. 1994. Das Ende des Automobils. Fakten und Trends zum Umbau der Automobilgesellschaft. Verlag C.F. Müller: Heidelberg.

Carlsson-Kanyama A, Linden AL 1999. Travel patterns and environmental effects now and in the future: implications of differences in energy consumption among socio-economic groups. Ecological Economics 30: 405-417.

Catton WR. 1987. The World's Most Polymorphic Species: Carrying Capacity Transgressed Two Ways. BioScience 37: 413-419.

Citlak B, Kreyenfeld M. 1999. Wahrnehmung von Umweltrisiken. Empirische Ergebnisse für die Bundesrepublik Deutschland. Zeitschrift für angewandte Umweltforschung 12: 112-119.

Cramer JC. 1998. Population Growth and Air Quality in California. Demography 35: 45-56.

Cramer JC, Cheney RP. 2000. Lost in the Ozone: Population growth and Ozone in California. Population \& Environment 21: 315-337.

Diekmann A, Preisendörfer P. 1992. Persönliches Umweltverhalten. Diskrepanzen zwischen Anspruch und Wirklichkeit. Kölner Zeitschrift für Soziologie und Sozialpsychologie 44: 226-251.

Ehrlich P, Holdren J. 1971. Impact of Population Growth. Science 171: 1212-1217.

Eisner M, Lamprecht M, Stamm H. 1993. Freizeit und Freizeitmobilität in der modernen Gesellschaft. In Wohnen mit dem Auto. Ursachen und Gestaltung automobiler Freizeit, Fuhrer U (ed); Zürich; 33-52

Engel U, Pötschke M. 1998. Willigness to pay for the environment: social structure, value orientation and environmental behaviour in a multilevel perspective. Innovation 11(3): 315-332.

Franzen A. 1997. Umweltbewusstsein und Verkehrsverhalten. Empirische Analysen zur Verkehrsmittelwahl und der Akzeptanz umweltpolitischer Massnahmen. Chur, Zürich.

Flade A. 1999. Begleitung und Transport von Kindern. In Frauen und Männer in der mobilen Gesellschaft, Flade A, Limbourg M (eds); Opladen; 257-262.

Greene WH. 1993. Econometric Analysis. Macmillan: New York.

Held M. 1984. Wertwandel und energierelevantes Verhalten der privaten Konsumenten. Zeitschrift für Umweltpolitik und Umweltrecht 3: 295-314.

Heigl A, Mai R. 1998. Demographische Alterung in den Regionen der EU. Zeitschrift für Bevölkerungswissenschaft 23: 293-317.

\footnotetext{
1 It remains to be seen whether the proposed causal structure between demographic characteristics and car use intensity, as mediated by various control factors, is stable. A longitudinal study that traces car use intensity in Austria back to the early 1980 's is currently in preparation by the authors.
} 
Jagodzinski W. 1986. Pfadmodelle mit latenten Variablen: Eine Einführung in das allgemeine lineare Modell LISREL. In Kausalanalyse (Techniken der empirischen Sozialforschung, 8), Hummell HJ, Jagodzinski W, Langeheine R (eds.); München; 77-121.

Kirchgässner G. 1992. Towards a theory of Low-cost Decisions. European Journal of Political Economy 8: 305320.

Krause C. 1997. Auto-Typen. PKW-Zielgruppenforschung mit den SINUS-Milieus. Media Spectrum 11/97: $32-$ 33.

List JA, Gallet, CA. 1999. The Environmental Kuznets Curve: Does One Size Fit All?. Ecological Economics 31: 409-423.

Lorbeer DA. 1996. Auto und Umwelt. Gegenwartskunde. Zeitschrift für Gesellschaft, Wirtschaft, Politik und Bildung 45/1: 101-111.

Lutzenhiser L, Hackett B. 1993. Social Stratification and Environmental Degradation: Understanding Household $\mathrm{CO}_{2}$ Production. Social Problems 40: 50-73.

MacKellar FL, Lutz W, Prinz C, Goujon A. 1995. Population, Households, and $\mathrm{CO}_{2}$ Emissions. Population and Development Review 21: 849-865.

Mensch K. 2000. Niedrigkostensituationen, Hochkostensituationen und andere Situationstypen: Ihre Auswirkungen auf die Möglichkeit von Rational-Choice-Erklärungen. Kölner Zeitschrift für Soziologie und Sozialpsychologie 52: 246-263

Mikl-Horke G, Leuker H. 1978. Das Auto als Verhaltensdeterminante (Berichte des Institutes für Allgemeine Soziologie und Wirtschaftssoziologie an der Wirtschaftsuniversität Wien 17). $2^{\text {nd }}$ edition, Wien.

Newman PWG, Kenworthy JR. 1988. The Transport Energy Trade-off: Fuel-efficient Traffic versus Fuel-efficient Cities. Transport Research A 22A: 163-174.

Österreichisches Statistisches Zentralamt (ed). 1995. Umweltbedingungen. Umweltverhalten. Ergebnisse des Mikrozensus Dezember 1994. Bearbeitet im Österreichischen Statistischen Zentralamt (Beiträge zur österreichischen Statistik 1222). Wien.

Österreichisches Statistisches Zentralamt (ed) 1996. Karte der NUTS-Gliederung Österreichs der Ebenen 1 bis 3. Wien.

Österreichisches Statistisches Zentralamt (ed) 1997. Statistisches Jahrbuch für die Republik Österreich, XLVIII. Jahrgang, N.F., 1997. Wien.

Österreichisches Statistisches Zentralamt (ed). 1998a. Energieverbrauch der Haushalte 1996/97. Ergebnisse des Mikrozensus Juni 1997. Bearbeitet im Österreichischen Statistischen Zentralamt (Beiträge zur österreichischen Statistik 1279). Wien.

Preisendörfer P. 1998. Umwelteinstellungen und Freizeitmobilität. Gibt es Effekte des allgemeinen Umweltbewußtseins auf das Verkehrsverhalten? Tourismus Journal 2: 441-456.

Preston SH. 1996. The effect of population growth on environmental quality. Population Research and Policy Review 15: 95-108.

Schupp J, Wagner G. 1998. Die Entwicklung der Umweltsorgen seit 1984 und ihre individuellen Determinanten. In Umwelt und empirische Sozial- und Wirtschaftsforschung (DIW Sonderheft 165), Schupp J, Wagner G (eds); Berlin; 172-173.

Sicher C. 1999. Alpenluft statt Abgasduft. EUROCITY. Österreichs grösstes Reisemagazin 4/99 (August/September): $58-59$

Simhandl G. 1998. Energieverbrauch der Haushalte 1996/97. Ergebnisse des Mikrozensus Juni 1997. Statistische Nachrichten 9/1998: 761-773.

Umweltbundesamt (ed). 1998. Umweltsituation in Österreich. Fünfter Umweltkontrollbericht des Bundesministers für Umwelt, Jungend und Familie an den Nationalrat. Wien.

Van der Gaag N, Van Imhoff E, Van Wissen L. 2000. Internal Migration Scenarios and Regional Population Projections for the European Union. International Journal of Population Geography 6: 1-19.

Wellner AS. 2000. Who is in the House?. American Demographics January 2000: 48-51.

Yamamoto T, Kitamura R. 2000. An analysis of household vehicle holding durations considering intended holding durations. Transportation Research A 34: 339-351. 